1. FCPS Medicine

Associate Professor of Medicine

Sheikh Zayed Medical College/

Hospital, Rahim Yar Khan

2. FCPS Cardiology

Assistant Professor Cardiology,

Sheikh Zayed Medical College/

Hospital, Rahim Yar Khan.

3. FCPS Medicine

Associate Professor of Medicine,

Sheikh Zayed Medical College/

Hospital, Rahim Yar Khan

Correspondence:

Dr. Muhammad Zafar Majeed Babar (FSPS Medicine)

Associate Professor of Medicine

Sheikh Zayed Medical College/

Hospital, Rahim Yar Khan

mzmbabar@yahoo.co.uk

Article received on:

02/08/2016

Accepted for publication:

15/10/2016

Received after proof reading:

$14 / 11 / 2016$

\title{
ACUTE MYOCARDIAL INFARCTION; EFFECTS OF THROMBOLYSIS ON TIMI FLOW RATE IN INFARCT RELATED ARTERY (IRA) IN PATIENTS OF ST ELEVATED ACUTE MYOCARDIAL INFARCTION. \\ mzmbabar@yahoo.co.uk \\ Dr. Muhammad Zafar Majeed Babar ${ }^{1}$, Dr. Abdul Majid², Dr. Javed Iqbal ${ }^{3}$
}

ABSTRACT... Objectives: To determine Post streptokinase TIMI flow grade (rate) in infarct related artery (IRA) in ST elevated myocardial infarction patients. Study Design: A nonrandomized prospective study. Period: Dec-2014 to Dec-2015. Setting: Sheikh Zayed Medical College and Hospital Rahim Yaar Khan. Methods: 113 patients were selected to see post streptokinase TIMI flow grade in infarct related artery (IRA). The data was analyzed using SPSS Version 20. Descriptive statistics was used to see and analyze the data. Results: Mean age of patients was $50.43 \pm 9.81$ years. There was more males $(87.61 \%)$ as compared to females (12.39\%). After thrombolyzation with streptokinase $23.01 \%$ patients were with TIMI grade 0/1 (failed perfusion), $45.13 \%$ (51) patients with TIMI grade 2 (partial perfusion) and $31.86 \%$ patients with TIMI grade 3 (full perfusion) in infarct related artery. In our study TIMI flow improved to grade $2 / 3$ (partial to complete perfusion) in $76.99 \%$ patients. There were $11.73 \%$ patients with TIMI 0/1 with 50\% ST segment resolved, $8.85 \%$ patients with TIMI 0/1 with persisted 50\% ST segment, $32.74 \%$ patients with TIMI 2 with $50 \%$ ST segment resolved, $11.5 \%$ (13) patients with TIMI 2 with $50 \%$ ST segment persisted, 32.74\% patients with TIMI 3 with 50\% ST segment resolved and $4.42 \%$ patients with TIMI $3 / 1$ with $50 \%$ ST segment persisted. Post streptokinase there was no coronary artery thrombus in $91.07 \%$ patients. While $6.25 \%$ patients had thrombus in left coronary artery and $2.84 \%$ patients had right coronary artery thrombus. Conclusion: Thrombolyzation with streptokinase improves perfusion in infarct related artery and increases TIMI flow grade in STEMI patients. It reduces the risk of recurrent myocardial infarction by restoration of blood flow in infarct related artery.

Key words: Thrombolysis, Streptokinase, TIMI flow

Article Citation: Babar MZ, Majid A, lqbal J. Acute myocardial infarction; effects of thrombolysis on Timi flow rate in infarct related artery (IRA) in patients of ST elevated acute myocardial infarction. Professional Med J 2016;23(11):1412-1416. DOI: 10.17957/TPMJ/16.3557

\section{INTRODUCTION}

ST segment elevation myocardial infarction, nonST segment elevation myocardial infarction and unstable angina are included in the category of acute coronary syndrome. ${ }^{1} \mathrm{Ml}$ occurs in about seven million people every year out of which $1 / 3$ rd die within an hour after infarction. ${ }^{2}$ The optimal management of $\mathrm{Ml}$ is the restoration of blood flow through the occluded artery as early patency of occluded artery has a benefit of increased survival in these patients. ${ }^{3}$

12- Lead electrocardiogram along with clinical symptoms provides a quick diagnosis of $\mathrm{MI}$ and helps us to decide which patient should be treated with thrombolysis for restoration of blood flow. Thrombolysis is routinely used to reopen the occluded artery after $\mathrm{Ml}$ and this treatment saves $0.30 \%$ lives if treatment is provided within 6 hours after Ml. ${ }^{3} \mathrm{It}$ is a safe, easy and cost-effective method to restore coronary perfusion. ${ }^{4}$ For success of thrombolysis, epical vessels flow is of prime importance because microcirculatory flow is of particular importance in patient outcomes. After thrombolysis, reperfusion of infarct related artery is usually achieved in $60-80 \%$ patients within 90 minutes of thrombolysis. And TIMI III flow is achieved only in $30-55 \%$ patients. In about $5-10 \%$ of these patients culprit artery is again occluded which may result in recurrent $\mathrm{Ml}$ and hence increased risk of mortality and morbidity. ${ }^{5}$ This study was conducted to determine Post streptokinase TIMI flow grade (rate) in infarct related artery (IRA) in ST elevated myocardial 
infarction patients.

\section{MATERIALS AND METHODS}

This was quasi experimental prospective study. The data was collected from Sheikh Zayed Medical College and Hospital Rahim Yaar Khan. The duration of study was from December 2014 to December 2015. 113 patients were included in the study. Non probability purposive sampling was used for data collection.

All ST elevated myocardial infarction patients thrombolyzed with streptokinase were included in this study. While Non ST elevated myocardial infarction patients and patients not thrombolyzed with streptokinase were excluded from the study. Electrocardiogram (ECG) was done in every patients after 90 minutes of thrombolysis to see ST segment resolution. Angiography was done in every patient 1 week after thrombolyzation to see the effectiveness of thrombolysis in terms of TIMI flow rates. A questionnaire was made to see post SK TIMI flow grade in IRA. All expected ECG changes, risk factors, complications, diagnoses, echo findings were included in the questionnaire.

Statistical analysis of data was performed using SPSS version 20. Descriptive statistics were used to see and analyses the data.

\section{RESULTS}

Out of one hundred and thirteen (113) patients, $12.39 \%$ (14) were females and $87.61 \%$ (99) were male. Mean age of patients was $50.43+9.81$ years. There were $29 \%$ diabetic, $37.17 \%$ smoker, and $29.2 \%$ hypertensive patients in this study. There were $11.50 \%$ patients with positive family history of acute coronary syndrome.

There were $20.35 \%$ anterior, $13.27 \%$ were anterolateral, $18.58 \%$ were antroseptal, $2.65 \%$ were lateral, $35.40 \%$ were inferior, $0.88 \%$ were inferolateral, $5.31 \%$ were inferoposterior, $0.88 \%$ were anteroinferior, $0.88 \%$ were posterolateral, $1.77 \%$ were posteroseptal STEMI.

There was no stenosis of left main stem artery in $90.27 \%$ patients.

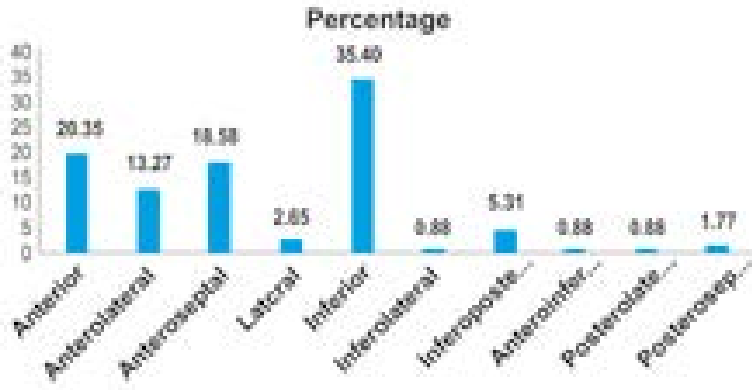

Figure-1. Types of ST Elevation Myocardial Infarction.

$0.88 \%$ patients had $80-100 \%$ stenosis, $2.65 \%$ patients had $70-80 \%$ stenosis, $1.77 \%$ patients had $50-70 \%$ and $4.42 \%$ patients had $<50 \%$ stenosis in left main stem. Regarding left anterior descending (LAD) artery, $16.81 \%$ patients had no stenosis (normal vessel). $9.73 \%$ patients had $100 \%$ stenosis, $28.32 \%$ patients had $80-100 \%$ stenosis, $30.09 \%$ patients had $70-80 \%$ stenosis and $0.88 \%$ patients had $50-70 \%$ stenosis and $7.08 \%$ patients had $<50 \%$ stenosis in LAD. While $7.08 \%$ patients had ecstatic LAD. Regarding left circumflex artery, 51.33\% Patients had no stenosis. $1.77 \%$ patients had $100 \%$ stenosis, $7.08 \%$ patients had $80-100 \%$ stenosis, $18.58 \%$ patients had $70-80 \%$ stenosis, $5.31 \%$ patients had $50-70 \%$ stenosis and $10.62 \%$ patients had $<50 \%$ stenosis in LCX. $5.31 \%$ patients had ectatic LCX. 35.45\% Patients had no stenosis in right coronary artery (RCA). $9.73 \%$ patients had $100 \%$ stenosis, $15.04 \%$ patients had $80-100 \%$ stenosis, $16.81 \%$ patients had $70-80 \%$ stenosis, $6.91 \%$ patients had $50-70 \%$ stenosis and $10.62 \%$ patients had $<50 \%$ stenosis in RCA.

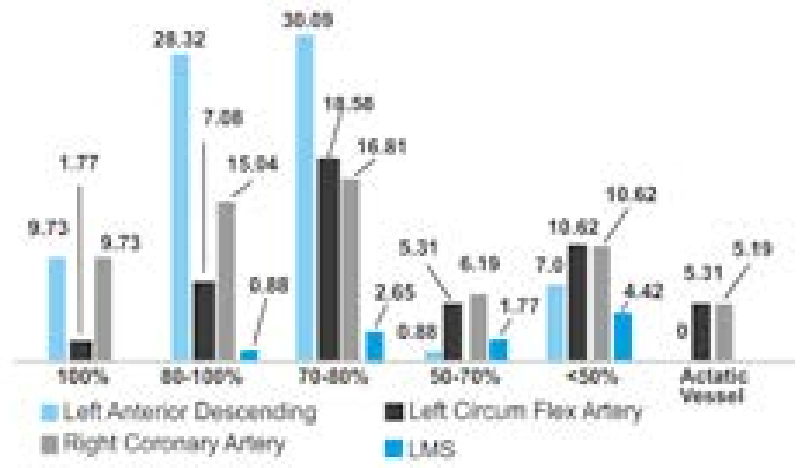

Figure-2. Percentage Stenosis of Individual Vessels.

In present study $23.01 \%$ (26) patients were with TIMl grade $0 / 1,45.13 \%$ (51) patients with TIMI grade 2 and $31.86 \%$ (36) patients with TIMI grade 
3. In our study TIMI flow improved to grade $2 / 3$ in $76.99 \%$ patients. There were $9.73 \%$ (11) patients with TIMI $0 / 1$ with $50 \%$ ST segment resolved, $8.85 \%$ (10) patients with TIMI 0/1 with persisted $50 \%$ ST segment, $32.74 \%$ (37) patients with TIMI2 with 50\% ST segment persisted, 32.74\% (37) patients with TIMI III with 50\% ST segment resolved and $4.42 \%$ (5) patients with TIMI II with $50 \%$ ST segment TIMI III with 50\% ST segment persisted resolved, 11.4\% (13) patients. In present study $43.36 \%$ patients had single vessel disease, $49.56 \%$ patients had double vessel and $7.08 \%$ patients had triple vessel disease. In $75.22 \%$ patients up to $50 \%$ decrease in ST segment elevations and $24.78 \%$ patients were without $50 \%$ decrease in ST elevation observed after 90 minutes of thrombolysation with streptokinase. Post streptokinase there was no coronary artery thrombus in $91.07 \%$ patients. while $6.25 \%$ patients had thrombus in left coronary artery and $2.84 \%$ patients had right coronary artery thrombus.

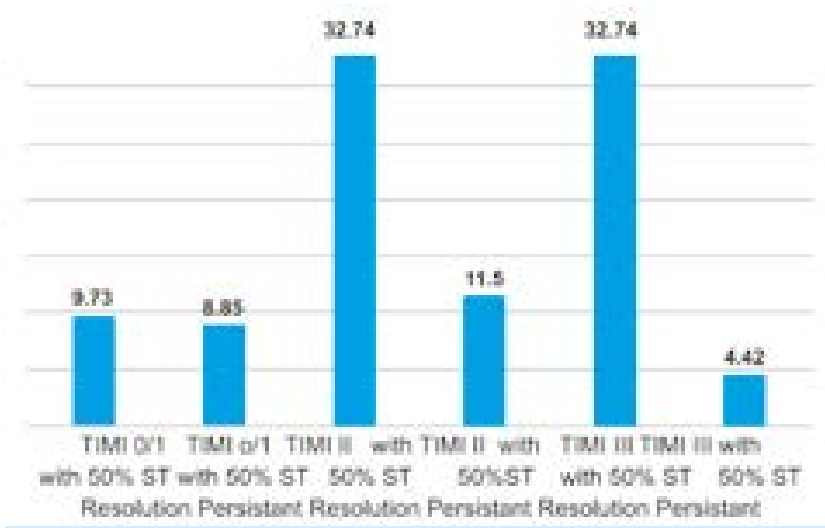

Figure-3. Relationship of TIMI Flow with $50 \%$ ST Resolution

\section{DISCUSSION}

This prospective study was designed to assess feasibility and potential benefits of treatment (thrombolyzation) with the streptokinase in patients of STEMI. Thrombolyzation with the streptokinase improves epicardial flow and coronary microcirculatory function. In our study 23.01\% (26) patients were with TIMI grade 0/1, $45.13 \%$ (51) patients with TIMI grade 2 and 31.86 $\%$ (36) patients with TIMI grade 3 . In our study TIMI flow improved to grade $2 / 3$ in $76.99 \%$ patients. White Trails supports our study .White trails $73 \%$ patients were in TIMI $2 / 3$ while $27 \%$ patients seen in TIMI 0/1. ${ }^{6}$
According to Simoons study, 90 minutes arterial patency rate after streptokinase was achieved in 50\%-60\%, and TIMI grade 3 flow was only achieved in $30 \%$ of the patients. ${ }^{7}$ According to Bhalla study TIMI 3 flow was achieved in $45 \%$ to $47 \%$ of patients ${ }^{8}$ and Andrews study documented that post streptokinase therapy, $28 \%$ had TIMI 0

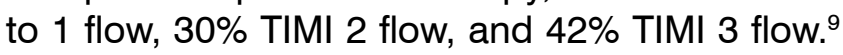
TIMI 3 flow was achieved in $38 \%$ of patients at streptokinase in Elliot study. ${ }^{10}$

As ST resolution is a useful and dependable marker for estimating micro-vascular perfusin. In present study, up to $50 \%$ ST-segment resolution was observed in $75.22 \%$ patients. According to de Lemon study there is complete ST segment resolution in $50 \%$ of patients treated wih streptokinase. ${ }^{11}$ In our study when we compared TIMI flow with up to $50 \%$ ST segment resolution then ,there were $9.73 \%$ (11) patients with TIMI 0/1 with $50 \%$ ST segment resolved, $8.85 \%$ (10) patients with TIMI $0 / 1$ with persisted $50 \%$ ST segment, $32.74 \%$ (37) patients with TIMI 2 with $50 \%$ ST segment resolved, $11.4 \%$ (13) patients with TIMI 2 with $50 \%$ ST segment persisted, $32.74 \%$ (37) patients with TIMI 3 with 50\% ST segment resolved and $4.42 \%$ (5) patients with TIMI 3 with 50\% ST segment persisted. Study of Sultana proved that $19 \%$ patients with TIMI $0 / 1$ with ST segment resolved, 25\% patients with TIMI 0/1 with persisted ST segment, 13.7\%patients with TIMI 2 with ST segment resolved, 21.5\% patients with TIMI 2 with ST segment persisted, $22 \%$ patients with TIMI 3 with ST segment resolved and $9.25 \%$ patients with TIMI 3 with ST segment persisted. ${ }^{12}$ Above mentioned studies took complete ST resolution with TIMI flow grade while in present study up to 50\% ST resolution (partial ST segment resolution) with TIMI flow grade was taken. It might be the reason for difference in results mentioned above The Reason of variation between our study and previous study results was due to the assessment of angiographic end point TIMI grading. Variability in the visual assessment of this end point hampers comparisons of flow data between thrombolytic agents and between trials because in addition to its subjective type the conventional flow-grading system is also categorical in nature. 


\section{CONCLUSION}

Thrombolyzation with streptokinase improves perfusion in infarct related artery and increases TIMI flow grade in STEMI patients. It reduces the risk of recurrent myocardial infarction by restoration of blood flow in infarct related artery. Copyright@ 15 Oct, 2016.

\section{REFERENCES}

1. Thygesen K, Alpert JS, Jaffe AS, Simoons ML, Chaitman $B R$, White HD. Third universal definition of myocardial infarction. Circulation. 2012;126(16):2020-35.

2. Hamid S, Kundal V, Mahajan N, Singh P. Failure of Thrombolysis with Streptokinase In Acute Myocardial Infarction Using ECG Criteria: An Observational Study. JK Sci. 2015;17(3).

3. Mauri F, Maggioni AP, Franzosi MG, De Vita C, Santqro $E$, Santoro L, et al. A simple electrocardiographic predictor of the outcome of patients with acute myocardial infarction treated with a thrombolytic agent: a Gruppo Italiano per lo Studio della Sopravvivenza nell'infarto Miocardico (GISSI-2)Derived Analysis. J Am Coll Cardiol. 1994;24(3):600-7.

4. Schröder R. Prognostic impact of early ST-segment resolution in acute ST-elevation myocardial infarction. Circulation. 2004;110(21):e506-e10.

5. Antman EM, Giugliano RP, Gibson $\mathrm{CM}, \mathrm{McCabe} \mathrm{CH}$, Coussement $P$, Kleiman NS, et al. Abciximab facilitates the rate and extent of thrombolysis results of the thrombolysis in myocardial infarction (TIMI) 14 trial. Circulation. 1999;99(21):2720-32.
6. White HD, Cross DB, Elliott JM, Norris RM, Yee TW. Long-term prognostic importance of patency of the infarct-related coronary artery after thrombolytic therapy for acute myocardial infarction. Circulation. $1994 ; 89(1): 61-7$.

7. Simoons M, Topol E, Califf R, van de Werf F, Armstrong $P$, Aylward $P E$, et al. An international randomized trial comparing four thrombolytic strategies for acute myocardial infarction. New Eng $\mathrm{J}$ Med. 1993;329(10):673-82.

8. Bhalla A, Kaur H, Sharma N, Varma S. Case Report Spontaneous Intra-Peritoneal Hematoma: An Unusual Complication of Thrombolysis.

9. Andrews J, Straznicky IT, French JK, Green CL, Maas $A C$, Lund $M$, et al. ST-segment recovery adds to the assessment of TIMI 2 and 3 flow in predicting infarct wall motion after thrombolytic therapy. Circulation. 2000;101(18):2138-43.

10. Elliot $M$, Immelman $E$, Jeffery $P$, Benatar S, Funston $\mathrm{M}$, Smith J, et al. A comparative randomized trial of heparin versus streptokinase in the treatment of acute proximal venous thrombosis: an interim report of a prospective trial. British J Surg. 1979;66(12):83843.

11. de Lemos JA, Braunwald E. ST segment resolution as a tool for assessing the efficacy of reperfusion therapy. J Am Coll Cardiol. 2001;38(5):1283-94.

12. Sultana R, Sultana N, Rasheed A, Rasheed Z, Ahmed $M$, Ishaq $M$, et al. Door to needle time of streptokinase and ST segment resolution assessing the efficacy of reperfusion therapy at Karachi Institute of Heart Diseases. J Ayub Med Coll Abbottabad. 2010;22(1).

\section{PREVIOUS RELATED STUDY}

Abdul Rehman Abid, Liaqat Ali, Tahir Mohyuddin, Shahid Naveed, Siraj Munir Ahmed, Muhammad Azhar. ACUTE MYOCARDIAL INFARCTION; EVIDENCE FOR A SEX-AGE INTERACTION (Original) Prof Med Jour 13(2) 178-185 Apr, May, Jun, 2006.

Aftab Ahmad, Zafar Hussain Tanvir, Zafar Hussain. ACUTE MYOCARDIAL INFARCTION; SERUM MAGNESIUM AND ELECTROLYTE LEVELS AT PRESENTATION IN EMERGENCY DEPARTMENT (Original) Prof Med Jour 17(2) 246-251 Apr, May, Jun 2010.

Ishtiaq Ahmed Malik, Khalid Mahmood, M Khalid Raja. ACUTE MYOCARDIAL INFARCTION (Original) Prof Med Jour 12(4) 457-465 Oct, Nov, Dec 2005.

Shahid Hafeez, Asim Javed, Azhar Mahmood Kayani. ACUTE MYOCARDIAL INFARCTION; SIGNIFICANCE OF 1ST SET OF CK-MB IN DIAGNOSIS(Original) Prof Med Jour 16(2) 198-201 Apr, May, Jun, 2009. 


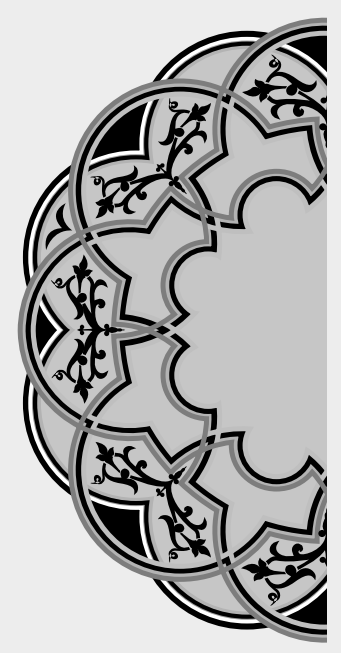

\title{
"Adversity causes some men to break, and others to break records."
}

\author{
Unknown
}

\begin{tabular}{|c|c|c|c|}
\hline \multicolumn{4}{|c|}{ AUTHORSHIP AND CONTRIBUTION DECLARATION } \\
\hline Sr. \# & Author-s Full Name & Contribution to the paper & Author $=\mathbf{s}$ Signature \\
\hline 2 & $\begin{array}{l}\text { Dr. M. Zafar Majeed Babar } \\
\text { Dr. Abdul Majid } \\
\text { Dr. Javed lqbal }\end{array}$ & $\begin{array}{l}\text { Conceived, Design and } \\
\text { wrote the manuscript } \\
\text { Did data collection, } \\
\text { helped in writing the } \\
\text { manuscript } \\
\text { Helped in statistical } \\
\text { analysis and } \\
\text { designing the research } \\
\text { Methodology, Review the } \\
\text { mnuscript }\end{array}$ & $\begin{array}{l}\text { Dreajact } \\
\text { at }\end{array}$ \\
\hline
\end{tabular}

